\title{
Speeded retrieval abolishes the false-memory suppression effect: Evidence for the distinctiveness heuristic
}

\author{
CHAD S. DODSON and AMANDA C. G. HEGE \\ University of Virginia, Charlottesville, Virginia
}

\begin{abstract}
We examined two different accounts of why studying distinctive information reduces false memories within the DRM paradigm. The impoverished relational encoding account predicts that less memorial information, such as overall familiarity, is elicited by the critical lure after distinctive encoding than after nondistinctive encoding. By contrast, the distinctiveness heuristic predicts that participants use a deliberate retrieval strategy to withhold responding to the critical lures. This retrieval strategy refers to a decision rule whereby the absence of memory for expected distinctive information is taken as evidence for an event's nonoccurrence. We show that the typical false-recognition suppression effect only occurs when the recognition test is self paced. This suppression effect is abolished when participants make recognition decisions under time pressure, such as within 1 second of seeing the test item. These results are consistent with the distinctiveness heuristic that a time-consuming retrieval strategy is used to reduce false-recognition responses.
\end{abstract}

There has been growing interest in mechanisms and procedures that reduce the occurrence of false memories (e.g., Benjamin, 2001; Dodson \& Schacter, 2001, 2002a, 2002b; Gallo, McDermott, Percer, \& Roediger, 2001; Hege \& Dodson, 2004; Schacter, Israel, \& Racine, 1999; Smith \& Hunt, 1998; see Dodson, Koutstaal, \& Schacter, 2000 , for a review). For example, with the DRM paradigm (e.g., Roediger \& McDermott, 1995) an increasing number of studies show reductions in false memories for related lure items when studied items were encoded in a distinctive manner, such as being presented with distinctive fonts, pictures, or anagrams (e.g., Arndt \& Reder, 2003; Dodson \& Schacter, 2001; Hicks \& Marsh, 1999; Schacter et al., 1999; Seamon et al., 2003).

Two different mechanisms can explain why studying distinctive information reduces false memories. One mechanism, which we call the distinctiveness heuristic, refers to a metacognitive retrieval strategy whereby people infer that an item is novel when they fail to remember expected memorial information about it (e.g., Dodson \& Schacter, 2002b; Gallo, Weiss, \& Schacter, 2004; Schacter et al., 1999). Despite a test item's high degree of familiarity, as in the case of a related lure item in the DRM paradigm, the absence of memory for expected distinctive information is evidence for the item's novelty. This strategy is consistent with the decision processes in Johnson and colleagues' source-monitoring framework

We are grateful for the helpful comments of Jason Arndt, Dave Gallo, Elliot Hirshman, Brian Nosek, Bethany Teachman, and Dan Willingham. Correspondence should be addressed to C. S. Dodson, Department of Psychology, P.O. Box 400400, 102 Gilmer Hall, University of Virginia, Charlottesville, VA 22904-4400 (e-mail: cdodson@ virginia.edu). (e.g., Johnson, Hashtroudi, \& Lindsay, 1993; see Dodson \& Schacter, 2002b, for a fuller discussion; for similar ideas, see Brewer \& Treyens, 1981; Collins, Warnock, Aiello, \& Miller, 1975; Hicks \& Marsh, 1999; Strack \& Bless, 1994).

An alternative mechanism for reducing false memories is one that we call impoverished relational encoding (e.g., Hege \& Dodson, 2004). According to this account, studying distinctive information interferes with the encoding of relational information. Because related lure items are associated with studied items, decreased memory for relational information would decrease responses to the critical lures. This account builds on Hunt and colleagues' distinction between item-specific and relational information (e.g., Hunt \& McDaniel, 1993; Smith \& Hunt, 1998; see also Arndt \& Reder, 2003). Focusing on the characteristics of the item, via distinctive encoding, may reduce false memories because it decreases the spread of activation from the studied items to the related lure (e.g., McEvoy, Nelson, \& Komatsu, 1999; Roediger, Balota, \& Watson, 2001; Roediger, Watson, McDermott, \& Gallo, 2001) or it decreases gist representations (e.g., Brainerd, Wright, Reyna, \& Mojardin, 2001).

The central difference between the foregoing mechanisms concerns the memorial information that is evoked by the related lures in the DRM paradigm after participants have encoded the items in a distinctive manner. The distinctiveness heuristic predicts that related lures elicit a high degree of familiarity that must be countered via this retrieval strategy. By contrast, the impoverished relational encoding account predicts that the critical lures elicit less memorial information after the studied items are encoded in a distinctive than in a nondistinctive manner. 
There is conflicting evidence in favor of both accounts. In support of the impoverished relational encoding account, we (Hege \& Dodson, 2004) observed that when participants were given recall instructions that should have disabled the distinctiveness heuristic, the critical lures were still less likely to come to mind after picture encoding than after word encoding. Regardless of whether participants were instructed to recall studied items only or to recall both studied items and items that were related to what was studied, such as critical lures, participants in a picture-encoding condition recalled fewer critical lures than did those in a word-encoding condition. Thus, in contrast to the distinctiveness heuristic, the related lures appear less available in general after distinctive encoding of the studied items. Further support for the impoverished relational encoding account comes from Arndt and Reder (2003), who presented some DRM lists at encoding in distinctive fonts and other lists in nondistinctive fonts. Participants showed lower false-recognition rates to critical lures that were related to the lists of items presented in the distinctive than in the nondistinctive fonts. These results pose problems for the distinctiveness heuristic, which would predict reduced false-recognition rates to all critical lures, as opposed to the observed selective reduction. Overall then, the foregoing studies are consistent with the impoverished relational encoding account's prediction that critical lures elicit less memorial information (e.g., less likely to come to mind and less familiar) after distinctive encoding of the studied items.

However, Schacter, Cendan, Dodson, and Clifford (2001) provided evidence in favor of the distinctiveness heuristic with a test instruction manipulation similar to the one used by Hege and Dodson (2004). Whereas Hege and Dodson examined recall performance, Schacter et al. examined recognition performance when participants were provided with test instructions that should either disable or enable the use of the distinctiveness heuristic. Specifically, when participants received inclusion recognition instructions to endorse both studied items as well as related items that matched the theme of previously studied items, there were no significant differences between the two encoding conditions in false-recognition rates to the critical lures. By contrast, when participants received standard recognition instructions to endorse studied items only, fewer critical lures were falsely recognized after picture encoding than after word encoding. This pattern of data suggests that a retrieval strategy underlies the false-recognition suppression effect because it is essentially turned off and on with a retrieval manipulation.

However, an alternative interpretation of the foregoing results, consistent with the impoverished relational encoding account, is that inclusion recognition instructions allow participants to compensate for a critical lure's lesser familiarity after picture encoding than after word encoding. For example, after studying desk, seat, sit, table, and so forth, participants could endorse the critical lure chair on an inclusion recognition test, not because it evokes a strong sense of familiarity, but because participants recognize during the test that chair is related to what was studied. This awareness would allow participants to recognize critical lures even though the lures themselves evoke little familiarity or other memorial information. Thus, the inclusion recognition test may mask differences in the amount of memorial information that is elicited by critical lures after picture encoding or word encoding.

The present study examined the distinctiveness heuristic and impoverished relational encoding hypotheses by comparing performance under speeded and nonspeeded recognition conditions. The distinctiveness heuristic is a particularly time-consuming process because participants must wait a certain amount of time in order to conclude that no expected memorial information has been retrieved. Therefore, a response deadline interrupts this strategy because participants no longer have any basis for inferring that the absence of memory for pictorial information means that the test item is new. Thus, even though this strategy is referred to as a "heuristic," this does not mean that it is fast acting. Under nonspeeded conditions, we should replicate existing studies and observe lower false-recognition rates of the critical lures after picture encoding than after word encoding. Speeded recognition conditions, however, should disable the use of the distinctiveness heuristic and, therefore, eliminate or reduce the false-recognition suppression effect that occurs after picture encoding as compared with word encoding. By contrast, the impoverished relational encoding account predicts that if the critical lures elicit more familiarity after word encoding than after picture encoding, this difference will be observable on both speeded and nonspeeded recognition tests. Many studies show that when different encoding conditions, such as different study-list lengths, alter overall recognition performance and presumably the overall amount of familiarity elicited by test items, these differences in performance between the conditions are observable under speeded test conditions as early as $700 \mathrm{msec}$ (e.g., Hintzman, Caulton, \& Levitin, 1998; Mulligan \& Hirshman, 1995; Nobel \& Shiffrin, 2001). Thus, this experiment is a deciding test of the distinctiveness heuristic.

\section{METHOD}

\section{Participants}

One hundred twenty-six University of Virginia undergraduate students participated in this study ( 83 female and 43 male), with 21 participants in each condition.

\section{Design and Materials}

A 2 (encoding condition: picture vs. word) $\times 3$ (time pressure: self-paced, 1,000 msec, $750 \mathrm{msec}$ ) between-subjects design was used. The stimuli consisted of 273 black-and-white pictures, (Schacter et al., 1999), which were based on the lists used by Roediger and McDermott (1995). These items were divided into 21 lists of semantically related items. Each list consisted of 12 related items and one critical, nonpresented lure. For counterbalancing purposes, the 21 lists were divided into three sets of 7 lists so that, across participants, each list appeared at study and also served as a source for 
Table 1

Probability of "Old” Responses on the Recognition Test as a Function of Item Type, Encoding Condition, and Time Pressure at Test

\begin{tabular}{|c|c|c|c|c|c|c|}
\hline \multirow[b]{3}{*}{ Item Type } & \multicolumn{6}{|c|}{ Encoding Condition } \\
\hline & \multicolumn{3}{|c|}{ Word } & \multicolumn{3}{|c|}{ Picture } \\
\hline & Self-Paced & $1,000 \mathrm{msec}$ & $750 \mathrm{msec}$ & Self-Paced & $1,000 \mathrm{msec}$ & $750 \mathrm{msec}$ \\
\hline True targets & .74 & .58 & .54 & .72 & .47 & .50 \\
\hline True target controls & .13 & .21 & .35 & .09 & .20 & .32 \\
\hline False targets & .51 & .54 & .56 & .30 & .47 & .54 \\
\hline False target controls & .11 & .26 & .42 & .06 & .18 & .41 \\
\hline
\end{tabular}

new words on the test. Each participant studied 14 lists, with 12 items per list. The recognition test consisted of fourteen false targets (nonpresented, critical lures), 7 false target controls (critical lures from 7 nonstudied lists), twenty-eight true targets (studied items), and 14 true target controls (unrelated new items), for a total of 63 test items. An additional 80 unrelated items were used in a separate practice session. The recognition test items were presented as words for all participants, regardless of encoding condition (e.g., Schacter et al., 2001).

\section{Procedure}

There were three consecutive stages: encoding, a practice phase for responding quickly, and a recognition test. During the encoding stage, all of the lists of related items were presented as a continuous sequence at a rate of one item every $3 \mathrm{sec}$. Each item was presented on the screen for $2 \mathrm{sec}$, and then a blank screen appeared for $1 \mathrm{sec}$ before the next study item was presented. In the pictureencoding condition, each item was presented as an auditory word with a corresponding picture; in the word-encoding condition, each item was presented as an auditory word and as a visual word. The participants were instructed to try to remember all of the items because a memory test would follow. After the encoding phase, all participants were given extensive practice responding under speeded conditions. This practice session consisted of two parts. First, the participants were presented with a list of 40 words to remember. These words were judged by the experimenters to be unrelated to any of the themes presented during the encoding stage. Then, the participants completed a speeded recognition test that was based on only these practice study items.

After the practice phase, the participants were presented with the instructions for the recognition test. All participants were informed that this test would consist of words and was based only on the information from the initial encoding phase. They were told to indicate whether each test item was "old" (i.e., it or a picture of it had been seen during the encoding phase) or "new" (i.e., it or a picture of it had not been seen during the encoding phase). The participants in the nonspeeded condition were informed that the test was selfpaced. By contrast, the participants in the 1,000-msec and 750-msec conditions were warned that they would have $1 \mathrm{sec}$ or $750 \mathrm{msec}$, respectively, to respond to each test item. In addition, they were informed that if they did not answer within that time limit, TOO SLOW would flash on the screen, accompanied by a loud beep. They were asked to respond as quickly as possible, in order to avoid the TOO SLOW warning. Because it was critical for the participants assigned to one of the speeded conditions to respond within the given time limit, an extra incentive was offered at the beginning of the final memory test. The participants were told that if they were able to respond in time, such that TOO SLOW appeared fewer than five times

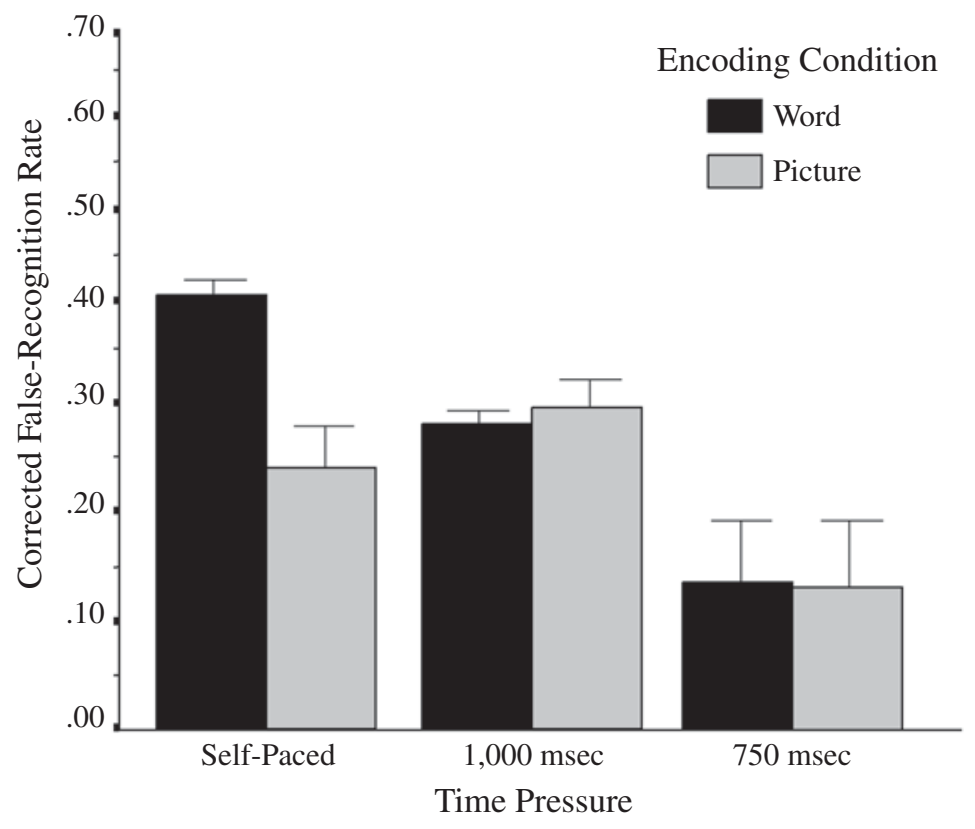

Figure 1. Corrected false-recognition rates for each time pressure condition after words or pictures were studied. Error bars indicate the standard errors of the means. 


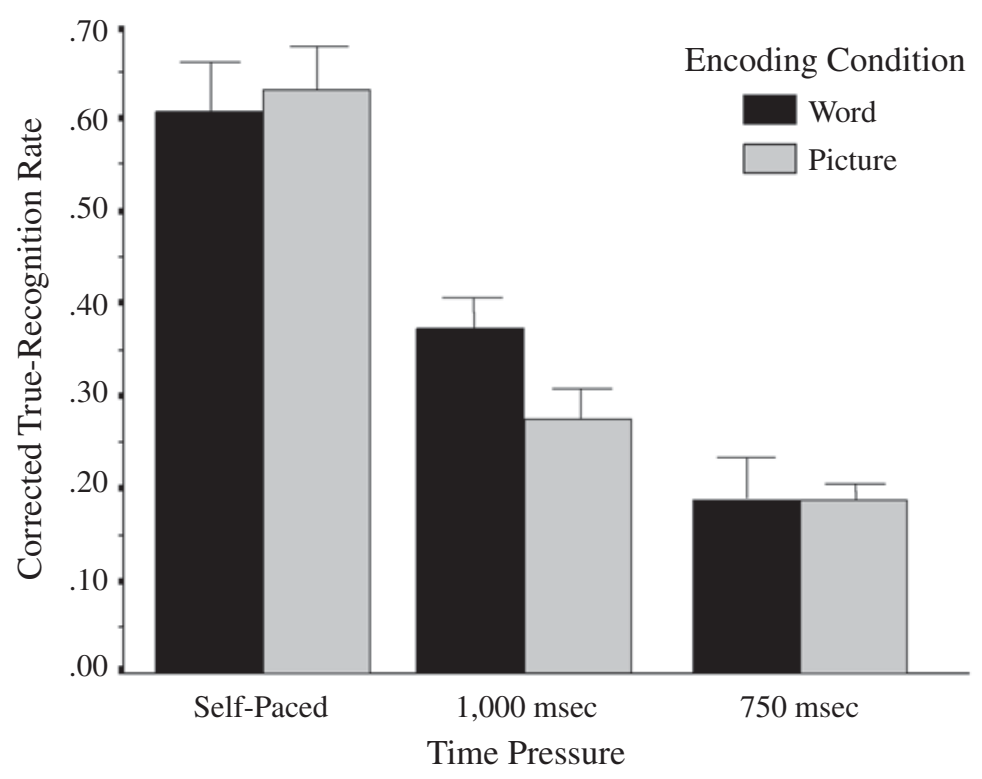

Figure 2. Corrected true-recognition rates for each time pressure condition after words or pictures were studied. Error bars indicate the standard errors of the means.

(i.e., less than $8 \%$ of the total number of test items), they would be paid an additional $\$ 2$. Nearly everyone (i.e., $96 \%$ of the participants) complied with these directions.

\section{RESULTS}

Table 1 shows the probabilities of responding "old" to targets (i.e., studied items), target controls (i.e., unrelated new words), false targets (i.e., critical lures), and false target controls (i.e., unrelated new words) under nonspeeded (i.e., self-paced) and speeded test conditions. Figures 1 and 2 present corrected false-recognition rates to the false targets and corrected true-recognition rates to the studied items, respectively.

As predicted by the distinctiveness heuristic, there was a significant suppression effect after picture encoding, relative to word encoding, in the self-paced condition but not in either of the speeded conditions. That is, participants falsely recognized fewer critical lures after picture encoding (30\%) than after word encoding $(51 \%)$ when the recognition test was self-paced $[t(40)=2.93$, $p<.01]$, replicating previous studies (e.g., Schacter et al., 2001; Schacter et al., 1999). By contrast, there were no significant differences between the two encoding conditions when the recognition test required a response within either $1,000 \mathrm{msec}[t(40)=1.10]$ or $750 \mathrm{msec}[t(40)<$ .40].

Moreover, the distinctiveness heuristic specifically predicts that the false-recognition suppression effect (i.e., the difference in false-recognition rates between the two encoding conditions) is greater when the recognition test is self-paced than when it is completed under time pressure. By contrast, the impoverished relational encoding account predicts comparable differences between the two encoding conditions at all test conditions. We measured the false-recognition suppression effect with difference scores that were derived by subtracting the false-recognition rate to the critical lures in the pictureencoding condition from this rate in the word-encoding condition. We then tested the predictions of the two hypotheses by performing a planned weighted contrast of the difference scores from the self-paced condition versus those of the combined speeded conditions. As predicted by the distinctiveness heuristic, there was a greater falserecognition suppression effect in the self-paced condition than in the speeded conditions, $\left[F(1,60)=8.87, M S_{\mathrm{e}}=\right.$ $0.079, p<.01]$.

Because there was some variability in false-recognition rates of the false target controls, we also performed the foregoing set of analyses on the corrected false-recognition rates of the false targets. As with the uncorrected scores, we replicated previous studies in the self-paced recognition condition and observed lower corrected false-recognition rates of the critical lures when participants studied pictures $(40 \%)$ than when they studied words $[24 \% ; t(40)=$ 2.21, $p<.05]$. And, as shown in Figure 1, there were nearly identical corrected false-recognition rates between the two encoding conditions under both of the speeded recognition conditions [all $t \mathrm{~s}(40)<.40$ ]. Importantly, the planned weighted contrast of the difference scores from the self-paced condition versus those of the combined speeded conditions was significant $[F(1,60)=$ 9.63, $\left.M S_{\mathrm{e}}=.078, p<.01\right]$. Overall then, this selective false-recognition suppression effect in the self-paced recognition condition fits the predictions of the distinctiveness heuristic.

With respect to true-recognition performance, Figure 2 shows that participants in the picture- and word-encoding 
conditions recognized similar amounts of studied items. Note that the picture superiority effect is typically not observed when the recognition test consists of words only (e.g., Dodson \& Schacter, 2002b; Jenkins, Neale, \& Deno, 1967; Schacter et al., 2001). Moreover, since participants were given less time to respond, true-recognition rates declined in the same manner, regardless of encoding condition. Since neither the distinctiveness heuristic nor the impoverished relational encoding account makes precise predictions about true-recognition performance, we conducted a 3 (time pressure: self-paced, 1,000 msec, $750 \mathrm{msec}) \times 2$ (encoding condition: picture vs. word) analysis of variance (ANOVA) of the recognition rates to studied items. This analysis yielded a significant effect of time pressure $\left[F(2,120)=19.55, M S_{\mathrm{e}}=0.03, p<.001\right]$, such that speeded responding produced lower recognition rates. There were no other significant effects. A 3 (time pressure: self-paced, $1,000 \mathrm{msec}, 750 \mathrm{msec}$ ) $\times 2$ (encoding condition: picture vs. word) ANOVA of the corrected recognition rates revealed the same pattern: a significant effect of time pressure $\left[F(2,120)=53.78, M S_{\mathrm{e}}=0.038\right.$, $p<.001]$ and no other significant effects. As is apparent in Figure 2, at each time pressure interval there was no difference in corrected recognition rates between the two encoding conditions [all $t \mathrm{~s}(40)<1.68$ ]

\section{DISCUSSION}

The central finding of this experiment is that time pressure, via speeded recognition responses, eliminates the false-recognition suppression effect that occurs after picture encoding. However, time pressure affects truerecognition rates in the same manner, regardless of encoding condition. These results are consistent with the distinctiveness heuristic, which holds that a time-consuming retrieval strategy is used to reduce false-recognition responses.

The present results do not support the impoverished relational encoding account, which argues that the critical lures should be less familiar after picture encoding than after word encoding. That is, since familiarity information is readily accessible under speeded and nonspeeded conditions, there should have been differences between the encoding conditions in false-recognition rates for the related lures on both tests. Therefore, this account can be ruled out because, contrary to its predictions, there were no differences between the encoding conditions in the false-recognition rates to the critical lures under speeded conditions. This lack of difference on the speeded tests suggests that picture encoding does not reduce the overall amount of familiarity that is elicited by the critical lure. Instead, picture encoding allows participants to use a metacognitive retrieval strategy-the distinctiveness heuristic - to counter familiarity-based responses that would otherwise lead to the occurrence of false recognitions under self-paced test conditions.

Two components of the distinctiveness heuristic make it vulnerable to disruption by speeded tests. First, participants must attempt and fail to recollect expected dis- tinctive information. There is accumulating evidence that the process of recollecting specific (e.g., pictorial) information is slower than the relatively fast process of retrieving familiarity information (e.g., Balota, Burgess, Cortese, \& Adams, 2002; Jacoby, 1999; Johnson, Kounios, \& Reeder, 1994; Joordens \& Hockley, 2000; McElree, Dolan, \& Jacoby, 1999). Second, participants must infer from this recollection failure that the test item is new because otherwise they surely would have recollected distinctive information about it. To put this all together, it appears that participants do not bother trying to use the distinctiveness heuristic on speeded tests because there is not enough time to complete both of the foregoing components. Instead, they simply rely on familiarity since it is readily accessible under speeded conditions. This account explains why false memories are suppressed under nonspeeded conditions (because participants have time to engage the recollection process and then use the distinctiveness heuristic) but not under speeded conditions.

Interestingly and speculatively, the speed at which one can use the distinctiveness heuristic may be influenced by the kind of expected information that one is failing to recollect. Johnson et al. (1994) observed that imagined information was recollected faster than was pictorial information, which suggests that one could sooner conclude that imagined information-rather than pictorial information-had not been recollected. The possibility about the relationship between the speed of using the distinctiveness heuristic and the type of information that one is failing to recollect awaits further research.

Our article is related to Benjamin (2001), who showed that speeded recognition limits the contributions of recollective processes to reducing false memories (see also Hintzman \& Curran, 1994). Benjamin observed that although critical lures are falsely recognized less often under self-paced recognition conditions when their related lists had been studied three times, rather than one time, this false-recognition suppression effect disappears under speeded recognition conditions. Moreover, since older adults exhibit deficient recollective processes, they show no reduction in false memories when the lists were studied three times, rather than one time. The distinctiveness heuristic, however, differs from the recollective mechanism in Benjamin's article in a crucial respect. Whereas Benjamin's mechanism appears to depend on successful recollection in order to reject the critical lures, the distinctiveness heuristic depends on attempting and failing to recollect expected information. Thus, in contrast to the recollective mechanism in Benjamin's article, the elderly are able to use the distinctiveness heuristic to reduce false memories because they also expect to remember pictorial information and respond accordingly when they fail to do so (see Dodson \& Schacter, 2002a, and Gallo, Weiss, \& Schacter, 2004, for a fuller discussion).

Finally, the present results, in conjunction with Hege and Dodson (2004), show that although picture encoding does not reduce the overall amount of familiarity that is elicited by the critical lures on a recognition test, it does interfere with the accessibility and recallability of the 
critical lures (see Hege \& Dodson, 2004, for a fuller discussion). The exact reason for the difference between recognition and recall tests awaits further research.

\section{REFERENCES}

ARndt, J., \& Reder, L. M. (2003). The effect of distinctive visual information on false recognition. Journal of Memory \& Language, 48, 1-15.

Balota, D. A., Burgess, G. C., Cortese, M. J., \& AdAMs, D. R. (2002). The word-frequency mirror effect in young, old, and early-stage Alzheimer's disease: Evidence for two processes in episodic recognition performance. Journal of Memory \& Language, 46, 199-226.

Benjamin, A. S. (2001). On the dual effects of repetition on false recognition. Journal of Experimental Psychology: Learning, Memory, \& Cognition, 27, 941-947.

Brainerd, C. J., Wright, R., Reyna, V. F., \& Mojardin, A. H. (2001). Conjoint recognition and phantom recollection. Journal of Experimental Psychology: Learning, Memory, \& Cognition, 27, 307-327.

BREWER, W. F., \& TREYENS, J. C. (1981). Role of schemata in memory for places. Cognitive Psychology, 13, 207-230.

Collins, A., Warnock, E. H., Aiello, N., \& Miller, M. L. (1975). Reasoning from incomplete knowledge. In D. Bobrow \& A. Collins (Eds.), Representation and understanding: Studies in cognitive science (pp. 383-415). New York: Academic Press.

Dodson, C. S., Koutstaal, W., \& Schacter, D. L. (2000). Escape from illusion: Reducing false memories. Trends in Cognitive Sciences, 4, 391-397.

DoDSON, C. S., \& SCHACTER, D. L. (2001). "If I had said it I would have remembered it": Reducing false memories with a distinctiveness heuristic. Psychonomic Bulletin \& Review, 8, 155-161.

Dodson, C. S., \& Schacter, D. L. (2002a). Aging and strategic retrieval processes: Reducing false memories with a distinctiveness heuristic. Psychology \& Aging, 17, 405-415.

Dodson, C. S., \& SchaCTER, D. L. (2002b). When false recognition meets metacognition: The distinctiveness heuristic. Journal of Memory \& Language, 46, 782-803.

Gallo, D. A., McDermott, K. B., Percer, J. M., \& Roediger, H. L., III (2001). Modality effects in false recall and false recognition. Journal of Experimental Psychology: Learning, Memory, \& Cognition, 27, 339-353.

Gallo, D. A., Weiss, J. A., \& Schacter, D. L. (2004). Reducing false recognition with criterial recollection tests: Distinctiveness heuristic versus criterion shifts. Journal of Memory \& Language, 51, 473-493.

Hege, A. C. G., \& Dodson, C. S. (2004). Why distinctive information reduces false memories: Evidence for both impoverished relationalencoding and distinctiveness heuristic accounts. Journal of Experimental Psychology: Learning, Memory, \& Cognition, 30, 787-795.

HICKS, J. L., \& MARSH, R. L. (1999). Attempts to reduce the incidence of false recall with source monitoring. Journal of Experimental Psychology: Learning, Memory, \& Cognition, 25, 1195-1209.

HintzMAN, D. L., \& CuRRAN, T. (1994). Retrieval dynamics of recognition and frequency judgments: Evidence for separate processes of familiarity and recall. Journal of Memory \& Language, 33, 1-18.

Hintzman, D. L., Caulton, D. A., \& Levitin, D. J. (1998). Retrieval dynamics in recognition and list discrimination: Further evidence of separate processes of familiarity and recall. Memory \& Cognition, 26, 449-462.

HUNT, R. R., \& McDaniel, M. A. (1993). The enigma of organization and distinctiveness. Journal of Memory \& Language, 32, 421-445.
JACOBY, L. L. (1999). Ironic effects of repetition: Measuring age-related differences in memory. Journal of Experimental Psychology: Learning, Memory, \& Cognition, 25, 3-22.

Jenkins, J. R., Neale, D. C., \& Deno, S. L. (1967). Differential memory for picture and word stimuli. Journal of Educational Psychology, 58, 303-307.

Johnson, M. K., Hashtroudi, S., \& Lindsay, D. S. (1993). Source monitoring. Psychological Bulletin, 114, 3-28.

Johnson, M. K., Kounios, J., \& Reeder, J. A. (1994). Time-course studies of reality monitoring and recognition. Journal of Experimental Psychology: Learning, Memory, \& Cognition, 20, 1409-1419.

JoORDENS, S., \& HoCKLEY, W. E. (2000). Recollection and familiarity through the looking glass: When old does not mirror new. Journal of Experimental Psychology: Learning, Memory, \& Cognition, 26, 1534-1555.

MCElReE, B., Dolan, P. O., \& JACOBY, L. L. (1999). Isolating the contributions of familiarity and source information to item recognition: A time course analysis. Journal of Experimental Psychology: Learning, Memory, \& Cognition, 25, 563-582.

MCEvoy, C. L., Nelson, D. L., \& Komatsu, T. (1999). What is the connection between true and false memories? The differential roles of interitem associations in recall and recognition. Journal of Experimental Psychology: Learning, Memory, \& Cognition, 25, 1177-1194.

Mulligan, N., \& Hirshman, E. (1995). Speed-accuracy trade-offs and the dual process model of recognition memory. Journal of Memory \& Language, 34, 1-18.

Nobel, P. A., \& SHIFFrin, R. M. (2001). Retrieval processes in recognition and cued recall. Journal of Experimental Psychology: Learning, Memory, \& Cognition, 27, 384-413.

Roediger, H. L., III, Balota, D. A., \& Watson, J. M. (2001). Spreading activation and the arousal of false memories. In H. L. Roediger III, J. S. Nairne, I. Neath, \& A. M. Surprenant (Eds.), The nature of remembering: Essays in honor of Robert G. Crowder (pp. 95-115). Washington, DC: American Psychological Association.

Roediger, H. L., III, \& McDermott, K. B. (1995). Creating false memories: Remembering words not presented in lists. Journal of Experimental Psychology: Learning, Memory, \& Cognition, 21, 803814.

Roediger, H. L., III, Watson, J. M., McDermott, K. B., \& Gallo, D. A. (2001). Factors that determine false recall: A multiple regression analysis. Psychonomic Bulletin \& Review, 8, 385-407.

Schacter, D. L., Cendan, D. L., Dodson, C. S., \& Clifford, E. R. (2001). Retrieval conditions and false recognition: Testing the distinctiveness heuristic. Psychonomic Bulletin \& Review, 8, 827-833.

Schacter, D. L., Israel, L., \& Racine, C. (1999). Suppressing false recognition in younger and older adults: The distinctiveness heuristic. Journal of Memory \& Language, 40, 1-24.

Seamon, J. G., Goodkind, M. S., Dumey, A. D., Dick, E., Aufseeser, M. S., Strickland, S. E., Woulfin, J. R., \& Fung, N. S. (2003). "If I didn't write it, why would I remember it?" Effects of encoding, attention, and practice on accurate and false memory. Memory \& Cognition, 31, 445-457.

SMITH, R. E., \& HUNT, R. R. (1998). Presentation modality affects false memory. Psychonomic Bulletin \& Review, 5, 710-715.

StraCK, F., \& Bless, H. (1994). Memory for nonoccurrences: Metacognitive and presuppositional strategies. Journal of Memory \& Language, 33, 203-217.

(Manuscript received February 12, 2004; revision accepted for publication September 23, 2004.) 